\title{
E-BOOK DE CIÊNCIAS COMO FERRAMENTA DE APOIO AOS PROFESSORES NA PROMOÇÃO DE AULAS PRÁTICAS
}

\author{
Geovane Rafael Theisen, UFSM, geovane theisen@ hotmail.com \\ Ana Cláudia Oliveira Pavão, UFSM, anaclaudiaoliveirapavao@gmail.com
}

\begin{abstract}
Resumo: Esse estudo teve como objetivo desenvolver um manual de práticas de ciências no formato e-book, como estratégia de ensino, para auxiliar professores do Nível Fundamental na promoção de aulas práticas. A pesquisa é de natureza aplicada e qualitativa. Os sujeitos são professores do ensino fundamental e os instrumentos de pesquisa foram questionários e ficha de avaliação/validação do e-book. Para a análise dos resultados utilizou-se a análise de conteúdo e referencial. Os resultados apontaram a necessidade de formação docente e melhoria na infraestrutura das escolas. Destaca-se, que o e-book apresenta elementos necessários para o desenvolvimento das aulas práticas de ciências.
\end{abstract}

Palavras-chave: E-book. Aulas práticas. Ensino de Ciências.

\section{SCIENCE E-BOOK AS A TOOL TO SUPPORT TEACHERS IN THE DEVELOPMENT OF PRACTICAL LESSONS}

\begin{abstract}
This study aimed to develop a handbook of science practices in the e-book format, as a teaching strategy, to assist teachers of the Fundamental Level in the development of practical lessons. The research is of an applied and qualitative nature. The subjects are elementary school teachers and the research instruments were questionnaire and evaluation/validation sheet of the e-book. For the analysis of the results was used the content and reference analysis. The results pointed out the need for teacher training and improvement in school infrastructure. It is noted that the e-book presents elements necessary for the development of practical science lessons.
\end{abstract}

Key words: E-book. Practical lessons. Science teaching.

\section{INTRODUÇÃO}

As aulas práticas de ciências propostas nas escolas têm sido tema de discussão na área educacional, devido às dificuldades de realizá-las no contexto escolar, principalmente pela falta de infraestrutura das instituições. Elas têm como objetivo complementar as aulas teóricas e sua utilização promove uma visualização e compreensão daquilo que antes estava presente apenas no imaginário dos alunos, motivando o interesse do aprendiz em continuar o processo de aprendizagem.

Dessa forma, como agentes ativos no processo de ensino e aprendizagem, é responsabilidade dos professores empregar metodologias e estratégias de ensino que minimizem as dificuldades e facilitem o aprendizado dos estudantes, aliando a teoria à prática.

As Tecnologias da Informação e da Comunicação (TIC) vem sendo utilizadas gradualmente como apoio didático-pedagógico. Barcelos, Passerino e Behar (2011) ressaltam a importância da preparação dos professores, para que possam integrar as tecnologias em suas práticas docentes e ratificam a importância da criação de novas propostas para integração das tecnologias digitais no processo de ensino e aprendizagem.

Entretanto, um fator relevante nesse processo é se apoderar do planejar. $\mathrm{O}$ planejamento, nas palavras de Santos e Vasconcelos (2019, p. 363) "exerce um papel 
fundamental em qualquer instância profissional e pessoal". Ainda, segundo os autores, permite aos docentes "repensar suas práticas e atitudes e criar estratégias e ambientes favoráveis para a aprendizagem".

Nesse sentido, Flôres e Tarouco (2008, p. 1) sinalizam o cuidado no desenvolvimento de materiais de auxílio para a aprendizagem, pois "uma quantidade enorme de materiais estão sendo desenvolvidos para suportar a educação e aprendizagem, entretanto avaliar sua qualidade e aplicabilidade para aprendizagem é muito difícil".

Ao encontro disso, Machado et al., (2018, p. 5) retratam que "o uso de computadores e dispositivos digitais, aliado ao uso da Internet, tem melhorado significativamente a quantidade e a qualidade dos materiais educacionais produzidos, bem como a dinâmica de interação entre professor e alunos".

Sendo assim, foi desenvolvido um manual de aulas práticas de ciências no formato de e-book com professores da rede pública de um município localizado no noroeste do estado do Rio Grande do Sul.

O recurso foi produzido para apoiar o processo de ensino e aprendizagem, visando contemplar a realidade das escolas e oferecer navegação amigável, interativa e de fácil acesso. A maioria das escolas dessa região apresentam uma infraestrutura precária e os professores não detêm um material de fácil entendimento para que possam preparar suas aulas. Assim, um e-book enquanto tecnologia de fácil acesso e entendimento, poderá sanar essa lacuna.

Valletta e Basso (2018) destacam que as ferramentas gratuitas e de baixo custo estão cada vez mais acessíveis e disponíveis para qualquer usuário com acesso à Internet. Porém, é preciso rever o método de ensino para o contexto contemporâneo. Os autores ainda retratam esse contexto:

Para ilustrar esse contexto massivo de informação e ferramentas deve-se compreender que hoje as acessamos [informação e ferramenta] de qualquer lugar e a qualquer momento quando estamos conectados e com o respectivo artefato adequado (VALLETTA e BASSO, 2018 p. 2).

Desta feita, Bottentuit Junior e Coutinho (2007) ressaltam que o e-book é um recurso didático que apresenta um enorme potencial, ainda mais se associado a dispositivos móveis que podem promover a popularização de uma prática que continua restrita àqueles que têm acesso à Internet e que dominam a utilização das tecnologias.

Portanto, a partir do desenvolvimento do manual de aulas práticas de ciências, no formato e-book, o objetivo deste estudo é investigar se esse recurso auxilia aos professores do Nível Fundamental, na promoção de aulas práticas.

\section{METODOLOGIA}

Este estudo se caracteriza como uma pesquisa de natureza aplicada, com abordagem predominantemente qualitativa. No entendimento de Triviños (2010, p. 131) "na pesquisa qualitativa, de forma muito geral, segue-se a mesma rota ao realizar uma investigação. Isto é, existe uma escolha de um assunto ou problema, uma coleta e análise das informações". Sendo assim, trata-se de um estudo descritivo e exploratório.

Os sujeitos desta pesquisa são 19 professores da área de Ciências/Matemática de 11 escolas de Ensino Fundamental da rede pública de um município localizado no noroeste do estado do Rio Grande do Sul, Brasil. O trabalho atuou com o intuito de ser um recurso didático de apoio, motivando os docentes no desenvolvimento de aulas práticas.

Os instrumentos de pesquisa constituíram-se de um questionário semiestruturado aplicado aos professores com a finalidade de investigar a formação inicial, prática de 
ensino, infraestrutura da escola, se desenvolve aulas práticas e qual a frequência, quais conteúdos seriam necessários em um manual com roteiros de atividades práticas, entre outras questões, para após, com base nesses resultados, ter condições de desenvolver o manual no formato de e-book. O segundo instrumento, compreendeu uma ficha de avaliação/validação do e-book, entregue aos professores, juntamente com o e-book.

Por meio da análise dos resultados do questionário aplicado previamente aos professores, desenvolveu-se o manual de aulas práticas que, em seguida, foi enviado aos docentes para aplicarem em suas turmas e avaliarem/validarem o recurso. Para a análise da ficha de avaliação/validação utilizou-se a análise de dados referencial (BARDIN, 2011).

A pesquisa foi desenvolvida em seis etapas. Primeiramente, buscou-se os referenciais teóricos que dessem suporte ao alcance do objetivo do estudo. A segunda etapa constituiu-se na seleção dos sujeitos, seguindo os procedimentos éticos para pesquisa com seres humanos. Na terceira etapa, foi aplicado o questionário e analisado os resultados. Na quarta etapa ocorreu o desenvolvimento do e-book, em que se buscou reunir roteiros de atividades sobre os conteúdos sugeridos pelos professores no questionário. A seleção e organização dos roteiros presentes no e-book foram adaptados pelos pesquisadores, por meio de atividades práticas disponíveis na internet com imagens, links de vídeos, jogos, documentários e atividades complementares, com o objetivo de tornar o produto interativo aos alunos e professores. A seleção do software seguiu os passos da pesquisa, utilizando o LibreOffice para edição do texto, em seguida, o Wrinter2ePub para criar o e-book. Por fim, utilizou-se o software FBReader que possibilita a leitura do e-book. Na quinta etapa foi realizada a Avaliação/Validação do Ebook, por meio de um formulário enviado aos professores participantes, o qual propunha uma avaliação por grau, conforme a Escala Likert, utilizando-se das opções: Concordo fortemente, Concordo, Incerto, Discordo e Discordo fortemente, permitindo que os docentes realizassem críticas e sugestões, quando necessárias, para complementar a avaliação e indicar os roteiros de práticas utilizados com suas turmas. A última etapa se constituiu na análise dos resultados e conclusões do estudo.

\section{RESULTADOS E DISCUSSÃO}

Com um total de 11 escolas da rede municipal participando do estudo, a amostra esteve constituída por 19 professores de Ciências/Matemática. Os sujeitos participaram duas vezes da coleta de dados, sendo que no primeiro momento, com o intuito de conhecer o público alvo e ter condições de elaborar o manual, apenas nove professores responderam ao questionário, e na segunda fase, ao avaliarem/validarem o e-book, 10 professores responderam o formulário online.

Importa referir que a coleta de dados seguiu os preceitos Éticos da Pesquisa com Seres humanos, regida pela Resolução n. ${ }^{\circ} 196196$ e seus adendos, garantindo o sigilo das informações prestadas pelos pesquisados. Dessa forma, respeitando o Termo de Consentimento Livre e Esclarecido (TCLE) e o Termo de Confidencialidade, mantendose o sigilo em relação a qualquer informação sobre os sujeitos da pesquisa, os professores são tratados pela letra $\mathrm{P}$, seguida do número 1 ao número 10 .

A figura 1 ilustra as respostas das dez perguntas, diante da questão geral: como você avalia o manual de aulas práticas de Ciências no formato e-book?. 
Figura 1: Resultados da avaliação/validação do e-book.

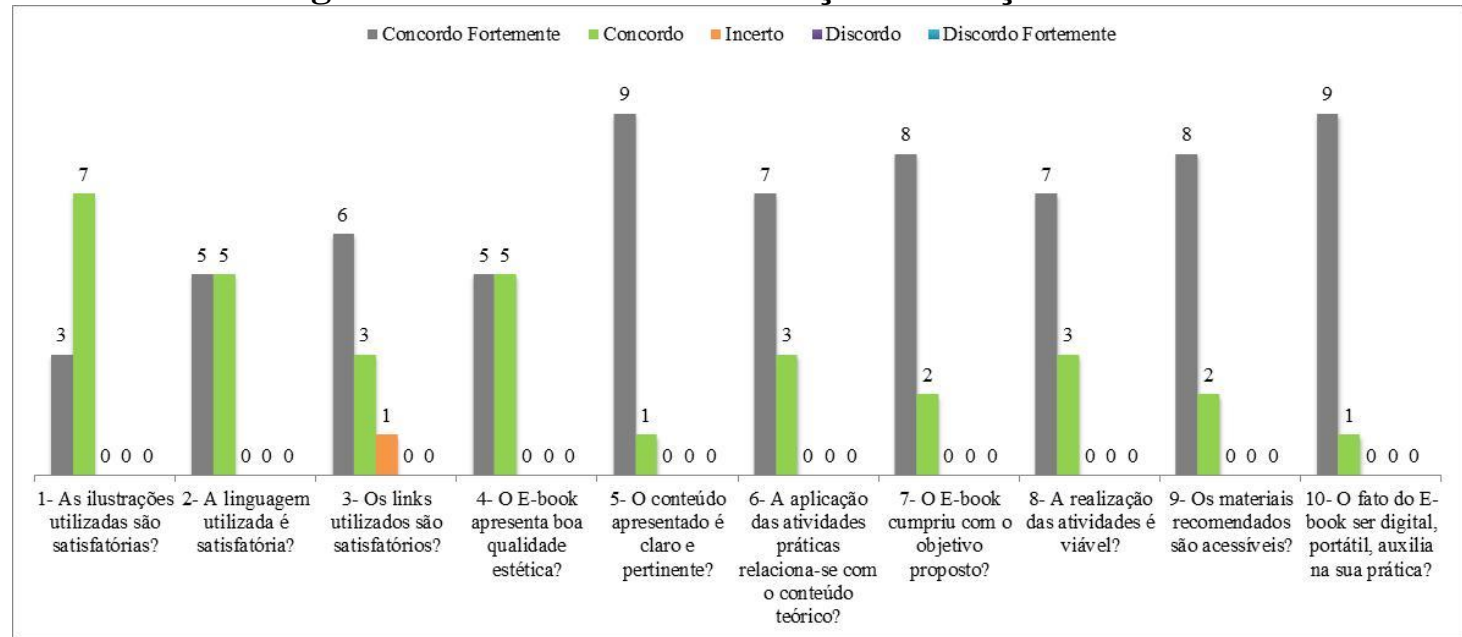

Fonte: elaborada pelos autores.

Diante da análise dos resultados da avaliação/validação, percebe-se que o manual correspondeu positivamente à maioria dos parâmetros avaliados. Observa-se que um docente encontrou alguma dificuldade ao utilizar os links presentes nos roteiros do ebook, marcando a opção "Incerto". Seis professores concordaram fortemente e três concordaram que os links utilizados são satisfatórios.

Em relação à inserção dos recursos multimídia, como os vídeos presentes no manual, Moran (1995) propõe um roteiro com algumas formas de trabalhar com o vídeo em sala de aula. Nesse sentido, os documentários e vídeos selecionados buscaram contemplar algumas dessas formas, quais sejam: sensibilização, ilustração, simulação e produção.

Ademais, de acordo com os professores, as atividades presentes no e-book apresentam qualidade estética, linguagem e ilustrações satisfatórias. Vale atentar, segundo Weber e Oliveira (2016), que materiais didáticos produzidos apresentam uma série de ferramentas visuais de design gráfico, além do conteúdo verbal e ilustrativo que constituem seu layout, objetivando promover a motivação e organização, aliados ao processo de aprendizagem.

Em contrapartida, a maioria das escolas apresentam várias tecnologias importantes para auxiliarem no processo de ensino-aprendizagem. Delizoicov, Angotti e Pernambuco (2011), enfatizam a necessidade do uso de diversas tecnologias que devem ser incorporadas pelo docente na prática do cotidiano escolar, pois "se o professor valoriza as atividades práticas e acredita que elas são determinantes para a aprendizagem de Ciências, possivelmente buscará meios de desenvolvê-las na escola e de superar eventuais obstáculos" (ANDRADE; MASSABNI, 2011, p. 836).

Na questão 5 referente ao conteúdo apresentado no e-book, nove professores concordaram fortemente e um concordou que é claro e pertinente. Quanto à aplicação das atividades práticas relacionadas com o conteúdo teórico, três docentes concordaram e sete concordaram fortemente. Oito professores concordaram fortemente quando questionados se o e-book cumpriu com o objetivo proposto e dois concordaram. Em relação à realização das atividades, três concordaram e sete concordaram fortemente que elas são viáveis. A média ou o somatório das respostas indica que o e-book apresenta potencial positivo para a promoção de aulas práticas de ciências.

Deste modo, o manual de práticas foi desenvolvido contemplando a realidade dessas escolas, com roteiros acessíveis, permitindo que as atividades sejam realizadas dentro da sala de aula, no laboratório de informática ou a campo. 
Santos (2007, p. 5) destaca que para o desenvolvimento de materiais didáticos:

[...] os autores deverão tomar decisões sobre quais são as características de um bom texto didático, que tipo de desenho e figura é mais adequado ao texto; que tipos de exercícios e exemplos são importantes; como incorporar nos materiais didáticos o saber prévio do aluno; como conciliar as imposições do currículo, as limitações do tempo ou estratégias de aprendizagem mais modernas.

Devido ao feedback dos 10 professores sobre o conteúdo, linguagem, ilustrações e hiperlinks expostos no e-book, o produto apresenta uma flexibilidade em atender às diferentes perspectivas, com maior ou menor ênfase, em determinados conteúdos, atendendo às demandas do currículo em cada escola.

Um mecanismo utilizado para tornar o manual versátil foi o uso de hiperlinks, permitindo acesso a atividades complementares, documentários e objetos interativos. Sobre a utilização de hiperlinks em softwares educativos, Reategui $(2007$, p. 6) enfatiza "é importante empregarmos convenções sedimentadas para identificação destes, como a utilização da cor azul para links textuais ainda não percorridos". Ainda, conforme o autor, "mecanismos de orientação e navegação eficazes permitem que os estudantes mantenham seu foco nos objetos de estudo e não precisem despender nenhum esforço para se localizar no software ou aprender a utilizá-lo".

Referente às questões 9 e 10, oito docentes concordaram fortemente e dois concordaram dizendo que os materiais recomendados no manual são acessíveis. Por fim, a pergunta se o fato de o manual ser digital e móvel, auxilia os professores na sua prática, os resultados apontaram nove docentes concordando fortemente e um professor que apenas concordou.

Ribeiro, Ferreira e Carneiro (2011) apresentam pressupostos nos quais assentam vantagens ao se adotar a aprendizagem móvel, como: a possibilidade de interação entre professor-aluno-aluno; a portabilidade e a colaboração, permitindo a mobilidade e o trabalho em conjunto de uma tarefa; a promoção do compromisso dos alunos, dada a grande aceitação de dispositivos móveis, aumentando assim a motivação e, por fím, a melhoria da autonomia e flexibilidade.

Todavia, alguns recursos e estratégias devem ser considerados durante a vivência e construção do conhecimento. $\mathrm{O}$ acesso a informações mínimas para possibilitar ao aluno a organização do conhecimento prévio, referências básicas e complementares, com a finalidade de instigar os estudantes em explorar os conteúdos e assuntos trabalhados em sala de aula.

Ao que tange às questões abertas da ficha de avaliação/validação, que procurou avaliar os roteiros das aulas práticas, pode-se constatar que todos os professores utilizaram, ao menos, um roteiro com a sua turma.

Conforme o P3, após utilizar as atividades 8 (Teoria da Biogênese) e 6 (Filo anelídeos), relatou o material pertinente e interessante: "Teoria da Biogênese mostrou-se pertinente no sentido de avaliar durante um maior período de tempo a evolução experimental, e assim, dar continuamente o andamento as atividades de ensino". Roteiro 6, "atividade muito interessante, pois introduz o conceito microscópico de vida, bastante difícil de visualizar sem o auxílio dessas imagens", destaca-se que nessa atividade está inserida uma imagem com a estrutura de um anelídeo (minhoca) em corte transversal visto por meio de um microscópio eletrônico.

O P5 declara ter utilizado dois roteiros: "utilizei em minhas aulas o roteiro que apresenta as vidrarias do laboratório, foi interessante para os alunos conhecerem o material e suas utilidades, pois a escola não possui laboratório de ciências. Também apresentei o microscópio, no qual foi possível utilizar o roteiro "conhecendo o 
microscópio". Foram atividades simples que contribuíram para introduzir a atividade científica, aguçando a curiosidade e ampliando a visão dos alunos sobre os seres vivos".

Já o P6 demonstra satisfação referente às atividades 1 e 7 "Olá, como estou estudando as plantas, consegui utilizar a atividade prática 1 (Observando as flores) e a atividade 7 (Pteridófitas). Nessas práticas foi possível realizar duas aulas diferenciadas e a campo com a turma. Os alunos demonstraram interesse e foi possível observar que após a prática tiveram facilidade em aliar a teoria. Em sala de aula utilizei as atividades do roteiro e também assistimos ao vídeo sobre as abelhas. A turma compreendeu a importância da preservação e o relatório dessas aulas foi satisfatório".

Sobre a atividade 5 o P7 discorre: "Somente consegui utilizar o roteiro da atividade número 5, sobre o Reino dos Fungos. Analisamos as leveduras (fermento biológico) e os bolores de frutas e pães. Foi solicitado aos alunos que trouxessem de casa o material para essa atividade. Após a observação assistimos o documentário proposto na atividade complementar e no laboratório de informática os alunos realizaram o quiz. Como incentivo, o aluno que obteve mais acertos ganhou um chocolate e os demais uma bala. A prática alcançou os objetivos propostos, integrou a teoria com a prática e se adaptou a realidade".

Nesta conjuntura, de acordo com a justificativa do P8, que só conseguiu apresentar a vidraria e o microscópio aos alunos e, devido à falta de tempo, não realizou outras práticas, é pertinente mencionar as condições de trabalho dos professores. Conforme Oliveira e Rosa (2017), a carga horária de trabalho, questões salariais, reconhecimento profissional, entre outros elementos faz com que, diante dessa realidade, muitas vezes, os professores assumam posturas antiéticas e acríticas durante o seu exercício laboral e não conseguem evitar tais ações, colocando em xeque sua prática pedagógica.

A segunda questão aberta do questionário de validação buscou a recolha de "Observações, sugestões e críticas" referentes ao e-book e teve como objetivo realizar possíveis correções/alterações, após a validação dos professores.

A primeira sugestão apareceu no relato do $\mathrm{P} 9$, que utilizou a prática número 3 (extração de DNA), e sugeriu a substituição do morango pela banana. "Atividade extração de DNA, no entanto foi substituído o morango pela banana, conforme sugestão no roteiro. A atividade foi incrível, a atenção dos alunos diante da prática só reforçou a importância da promoção delas. O produto será muito bem aproveitado em minhas aulas."

A resposta do P2 gerou dúvida e incerteza, pois apenas inseriu três pontos de interrogação “???”. Infelizmente pela ausência da justificativa e, sem o motivo declarado, não há como saber se houve algum problema no acesso ao material, ou o docente não utilizou os roteiros por falta de interesse, de tempo, haja vista que o produto foi encaminhado aos contatos disponibilizados no início da pesquisa e também via WhatsApp.

No entanto, a análise das respostas dos professores 3 e 8 , sinaliza satisfação com o resultado do e-book, conforme relatam: "A ferramenta foi importante para ilustrar o conhecimento, despertar o interesse, e trazer de forma mais didática aos alunos os diferentes níveis de conhecimento dentro do mesmo de ciências. Experiência muito gratificante e de grande validade!" (P3); "Material de boa qualidade, útil e facilitador ao professor para realizar as atividades em aula com uso de dispositivo móvel (P8)".

Diante do feedback dos professores, pode-se inferir que o produto demonstrou positivamente a usabilidade da interface. Nas palavras de Reategui (2007, p. 6):

A usabilidade mede a qualidade da experiência de um usuário quando interage com um produto ou sistema. Em geral, a usabilidade se refere à facilidade que 
os usuários têm em aprender a utilizar um produto para alcançar seus objetivos, e o quão satisfeitos ficam com o processo.

Nesse contexto, Wardeiner (2007) aponta cinco fatores que podem medir a usabilidade de uma interface, são elas: facilidade de aprendizagem que está relacionada ao emprego de mecanismos de orientação e navegação; eficiência de uso e frequência de erro e severidade relacionados à utilização de mecanismos de interação; memorização densidade de informações presentes nas telas, ou seja, o layout; e satisfação subjetiva ligada principalmente a fatores como estética e afetividade. A Figura 2 apresenta um dos roteiros práticos de ciências que foi desenvolvido com o auxílio dos professores e o endereço do e-book, para utilização do material.

\section{Figura 2: Roteiro de aula prática Fungos}
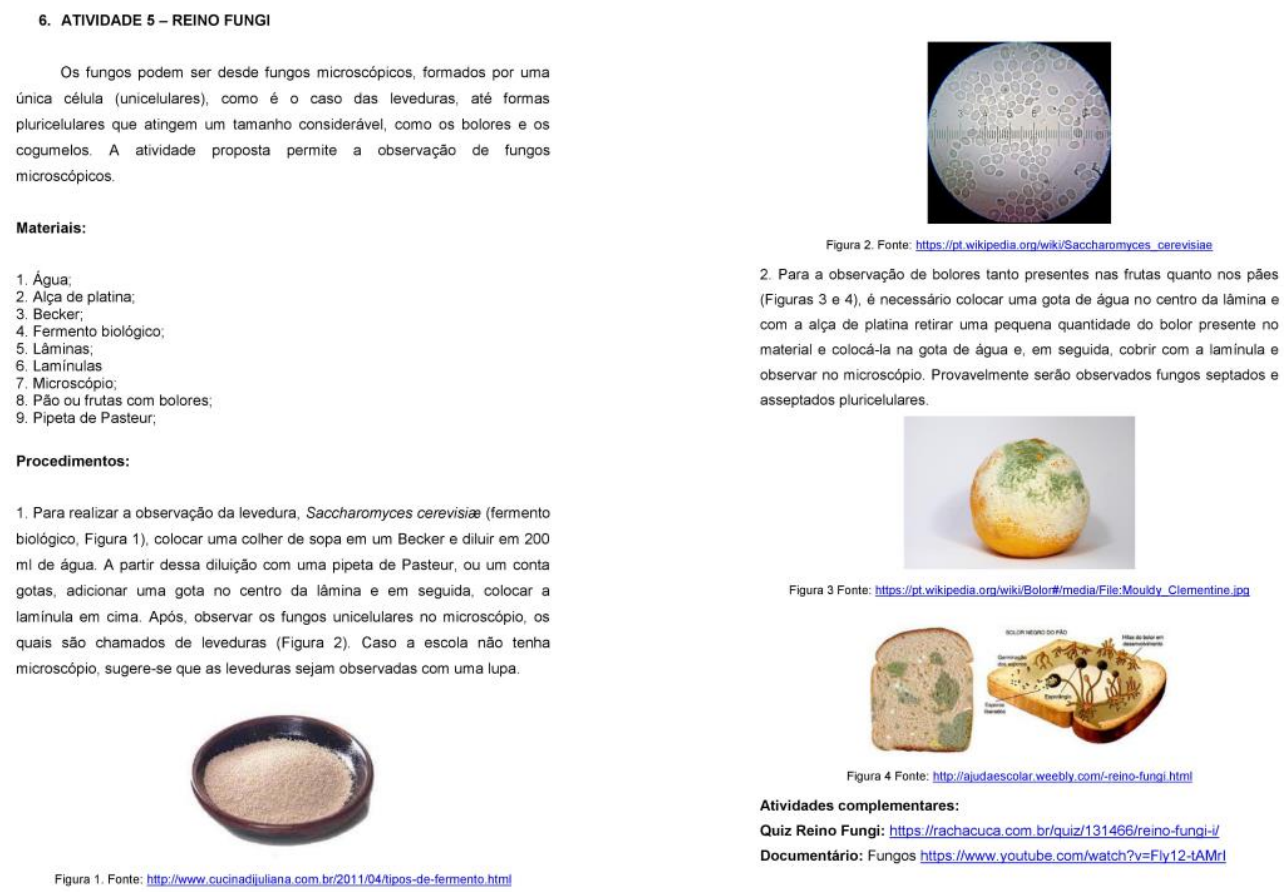

Fonte: Dos autores. http://ppgter.ufsm.br/images/Produto_Mestrado_Geovane_Theisen_PDF.pdf

Portanto, as declarações evidenciam que o e-book de aulas práticas constitui um importante recurso metodológico facilitador do processo de ensino e aprendizagem, despertando a curiosidade e o interesse dos alunos, atendendo ao objetivo proposto e confirmando o potencial que apresenta para auxiliar os professores na prática docente.

Pode-se inferir que a tecnologia trouxe novas possibilidades e desafios para os professores. Entende-se que a infraestrutura de uma instituição educacional é necessária para oportunizar a formação do alunado, porém, conforme Valletta e Basso (2018, p. 10) destacam "os dispositivos pessoais são exemplos de que é possível instrumentalizá-los para uma didática que rompa a cultura predominante do método tradicional de ensino". E dominar a técnica, pode promover experiências inovadoras.

\section{CONCLUSÕES}


O e-book é um produto que agrega as variadas artes, a música, o vídeo, o design, a fotografia, e, ainda, a interatividade, o movimento e a construção em rede. Com isso, torna-se indispensável o professor apropriar-se de recursos para promover um ensino de qualidade, autonomia e emancipação aos estudantes no processo de ensinoaprendizagem.

Após a disponibilização do manual no formato de e-book foi possível constatar a satisfação dos docentes com as aulas ministradas por meio dos roteiros disponíveis no produto. A aplicação do primeiro questionário possibilitou conhecer a estrutura física das escolas e percebeu-se que a maioria dos professores raramente incluem atividades práticas em suas aulas devido às escolas estarem desprovidas de laboratório de ciências. No entanto, reitera-se que essa condição não é necessária para a realização da experimentação proposta no e-book.

Dentre as limitações, uma delas diz respeito às desvantagens no uso do e-book, ou seja, as dificuldades técnicas, pois para viabilizar a leitura do manual é necessário o uso de um software para sua decodificação/leitura, um reader. Também, existem questões financeiras e econômicas que permeiam esse processo, no entanto, utilizou-se um software gratuito com o intuito de permitir o acesso para todos os professores.

Outra questão importante que indica limitação nesse estudo refere-se ao retorno dos questionários pelos professores. Percebeu-se que muitas respostas não foram exploradas suficientemente nas duas fases da pesquisa, no desenvolvimento do e-book e na geração de dados que apontam carências e/ou necessidades de retificações ou correções.

O estudo apontou que os professores se sentiram motivados em utilizar o e-book pela sua versatilidade, pois é um material interativo, contém texto, imagens, atividades complementares, hiperlinks de vídeos, documentários, jogos interativos e quiz, e permite a inclusão de comentários pelo leitor, bem como o controle e ajuste de nuances de brilho, cor e tamanho da fonte. Além disso, o e-book colabora para a preservação ambiental, pela economia de papel gerada.

Por fim, a contribuição do estudo realizado nesse trabalho não teve a pretensão de esgotar as discussões referentes ao tema, mas despertar a possibilidade de desenvolvimento de novos objetos de investigação, assim como evidenciar a importância das atividades práticas na consolidação do conhecimento e apontar o potencial que o ebook tem, para auxiliar os professores na prática docente.

\section{REFERÊNCIAS BIBLIOGRÁFICAS}

ANDRADE, M. L. F.; MASSABNI, V. G. O desenvolvimento de atividades práticas na escola: um desafio para os professores de ciências. Ciência \& educação, v. 17, n. 4, p. 835-854, 2011.

BARCELOS, G. T.; PASSERINO, L. M.; BEHAR, P. A. Redes sociais na internet: ambiente pessoal de aprendizagem na formação de professores iniciantes de matemática. Revista Novas Tecnologias na Educação, v. 9, n. 1, 2011.

BARDIN, L.; Análise de conteúdo. São Paulo: Edições 70, 2011.

BOTTENTUIT JUNiOR, J. B.; COUTINHO, C. P. A Problemática dos E-Books: um

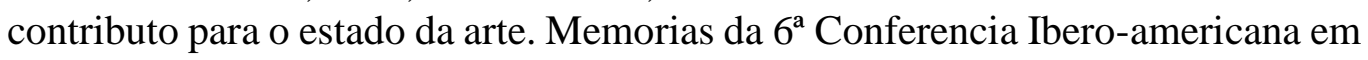
Sistemas, Cibernética e Informática, v. 2, 106-111, 2007. Disponível em: $<$ http://repositorium.sdum.uminho.pt/bitstream/1822/6717/1/book.pdf $>$ Acesso em: 07 fev. 2019.

DELIZOICOV, D.; ANGOTTI, J. A.; PERnAMBUCO, M. M. Ensino de Ciências Fundamentos e Métodos. São Paulo: Cortez, 2011. 
FLÔRES, M. L. P.; TAROUCO, L. M. R. Diferentes tipos de objetos para dar suporte a aprendizagem. Revista Novas Tecnologias na Educação, v. 6, n. 1, 2008.

MACHADO, G. B.; KUHN, I.; SANTOS JR. F. D. dos, WIVES, L. K. Um Estudo Sobre o Perfil de Professores do Ensino Fundamental e o Uso de Tecnologias para a Educação: uma Proposição de Agenda de Pesquisa a partir de Dados Educacionais. Revista Novas Tecnologias na Educação, v. 16, n. 2, 2018.

MORAN, J. M. O vídeo na sala de aula. Comunicação \& Educação, v. 1, n. 2, p. 27-35, 1995.

OLIVEIRA, B. C.; ROSA, F. S. A. Um Novo Olhar para a Prática Docente. Trabalho de Conclusão do Curso de Especialização em Docência do Ensino Superior da Universidade Federal do Triângulo Mineiro (UFTM), Uberaba - MG, 2017.

RIBEIRO, A.; FERREIRA, E.; CARNEIRO, N. Mobile Learning - As tecnologias telemáticas e a aprendizagem, 1-25, 2011. Disponível em: <https://www.slideshare.net/ElisabeteFerreira/mobile-learningmestradomultimedia > Acesso em: 10 fev. 2019.

REATEGUI, E. Interfaces para softwares educativos. Revista Novas Tecnologias na Educação, v. 5, n. 1, 2007.

SANTOS, F. M. T. Unidades temáticas - produção de material didático por professores em formação inicial. Experiências em Ensino de Ciências, v. 2, n. 1, 1-11, 2007.

SANTOS, J. E. B. dos; VASCONCELOS, C. A. Formação continuada com tecnologias: metanálise a partir de dissertações e teses (2013-2017). Educ. Matem. Pesq., São Paulo, v. 21, n. 1, p. 361-382, 2019.

TRIVIÑOS, A. N. S. Introdução à pesquisa em ciências sociais: a pesquisa qualitativa em educação. São Paulo: Atlas, 2010.

WARDEINER, M. R. Usability Engineering Team: Design Guidelines. NASA Glen Research Center, 2007.

WEBER, D. J.; OLIVEIRA, L. R. Materiais Didáticos para Educação a Distância: Observando Layouts. Revista Científica em Educação a Distância, v. 6, n. 1, p. 152-167, 2016.

VALLETTA, D.; BASSO, M. Gênese instrumental e o fenômeno da ubiquidade na formação docente. Revista Novas Tecnologias na Educação, v. 16, n. 1, 2018. 